\title{
Bullying homofóbico: Crenças e práticas de estudantes do Ensino Superior em Portugal
}

\author{
Sofia Neves ${ }^{1,2}$, Janete Borges ${ }^{1}$, Estefânia Silva ${ }^{1,2}$, Cristina Pereira Vieira ${ }^{2,3}$ \& Ana Neves \\ Sousa ${ }^{1}$ \\ ${ }^{1}$ Instituto Universitário da Maia \\ ${ }^{2}$ Centro Interdisciplinar de Estudos de Género (ISCSP-ULisboa) \\ 3 Universidade Aberta
}

\begin{abstract}
Resumo: 0 presente estudo teve como objetivo caracterizar as crenças e as práticas de um grupo de 369 estudantes do Ensino Superior português, 282 do sexo feminino e 84 do sexo masculino, com uma média de idades de 21.49, relativamente ao bullying homofóbico. A partir do preenchimento de uma ficha sociodemográfica e de três Inventários, concluiu-se que os homens praticam e sofrem mais bullying homofóbico do que as mulheres. Os/As estudantes portugueses/as que praticam comportamentos violentos contra pessoas lésbicas e gays (LG) apresentam crenças mais conservadoras sobre a orientação sexual LG e sobre o género do que os/as que não praticam. As pessoas que revelam crenças sobre a orientação sexual LG mais conservadoras são também aquelas que revelam crenças de género mais conservadoras $(\mathrm{r}=0.423, \mathrm{p}<0.001)$. Os homens revelam crenças sobre a orientação sexual LG mais conservadoras $(\mathrm{t}(102.046)=-4.908, \mathrm{p}<.001)$, sendo também os que praticam mais violência contra pessoas LG.
\end{abstract}

\section{Palavras-chave: Bullying; género; homofobia; Portugal.}

Homophobic Bullying: Beliefs and practices of higher education students in Portugal: The study aimed to characterize beliefs and practices of a group of 369 Portuguese college students, 282 female and 84 male, with an average age of 21.49, concerning homophobic bullying. Based on a sociodemographic report and three Inventories, we concluded that men are more victims and aggressors of homophonic bullying than women. Portuguese students who practice more violent behaviors against lesbian and gay (LG) people present more conservative beliefs on LG sexual orientation and gender, comparing to those who are not violent. People who reveal more conservative beliefs on LG sexual orientation are also who reveal more conservative beliefs on gender $(\mathrm{r}=0.423, \mathrm{p}<0.001)$. Men holds more conservative beliefs than women on LG sexual orientation $(\mathrm{t}(102.046)=-4.908, \mathrm{p}<.001)$, presenting also high values of violence against LG people.

Keywords: Bullying; gender; homophobia; Portugal.

O bullying homofóbico, aqui entendido como a prática ou a intenção de praticar comportamentos violentos em razão da orientação sexual gay, lésbica ou bissexual da vítima ou da sua presunção (Hong \& Garbarino, 2012), afigura-se como um fenómeno alarmante, quer do ponto de vista da sua magnitude, quer do ponto de vista das suas implicações (Monk, 2011).

De acordo com Meyer (2008), o bullying homofóbico, ou o bullying LGBTI-fóbico (Otero \& Martínez, 2006), é também uma forma de violência baseada no género que consiste na atribuição de rótulos pejorativos ou na adoção de comportamentos e/ou expressões humilhantes contra jovens que são percebidos/as como gays, lésbicas, bissexuais, queer ou não conformes. Diversos estudos (e.g., Friedman et al., 2011) têm vindo a demonstrar que os/as jovens LGBT (lésbicas, gays, bissexuais e trans) são um grupo especialmente vulnerável à prática do bullying. Com efeito, quer o género das vítimas, quer a sua orientação sexual, têm vindo a ser consistentemente apontados pela Literatura como fatores de risco para este tipo particular de vitimação, sendo que os gays, as lésbicas e as mulheres bissexuais estão habitualmente em maior risco de vitimação do que os homens e as mulheres heterossexuais (FRA, 2014).

Sendo uma forma muito específica de vitimação, que pode provocar danos físicos, psicológicos e sociais severos, o bullying homofóbico começa a manifestar-se, grosso modo, na fase da adolescência e

${ }_{1}^{1}$ Morada de correspondência: Sofia Neves, Instituto Universitário da Maia, Avenida Carlos Oliveira - Castêlo da Maia, 4475-690 Avioso S. Pedro, Portugal. E-mail: asneves@ismai.pt 
início da vida adulta em áreas como a social, a escolar e a profissional (Bacon, 2011; Espelage, Aragon, Birkett \& Koenig, 2008; 0'Higgins-Norman, 2008). A par dos efeitos que o bullying, de um modo geral, provoca, o homofóbico, em particular, tem como consequências mais comuns o desenvolvimento de perturbações depressivas e de ansiedade, o abuso de substâncias, o isolamento social, a manifestação de comportamentos sociais disruptivos, a auto-mutilação, o absentismo escolar e a ideação suicida (Adams, Cox, \& Dunstan, 2004; Ferreira, 2013; Fonseca, 2015; Pimenta, 2013; Robertson, \& Monsen, 2001). Se se considerar que muitos/as destes/as jovens são hostilizados/as e/ou rejeitados/as pela família e pelos grupos de pares, tendo por isso a sua rede de suporte fragilizada ou mesmo diminuída (Rodrigues, Grave, Oliveira, \& Nogueira, 2016; Ryan, Huebner, Diaz, \& Sanchez, 2009; UNESCO, 2012), a vulnerabilidade a que estão expostos/as agudiza-se.

Tal como acontece com outras variantes do bullying, nos casos do homofóbico as vítimas tendem a ser percecionadas pelos/as agressores/as como alvos fáceis, por apresentarem características distintas das deles/as, seja quanto à orientação sexual, às características psicológicas, físicas e/ou sociais (Fonseca, 2015). Adicionalmente, as diferenças culturais, a pertença étnica e a diversidade funcional são critérios de seleção para os/as agressores/as (Pimenta, 2013), escolhendo estes/as vítimas que aparentam ter menos competências e recursos para se defender das suas investidas. Intersectam-se, muitas vezes, com a orientação sexual, outros eixos de vulnerabilidade (e.g., género, etnia) que aumentam o risco de exposição à discriminação e à violência (Misawa, 2010).

Mantendo, por norma, uma postura dominante ao longo de todo o processo, os/as bullies - jovens provenientes, muitas vezes, de ambientes familiares e sociais onde a punição física é encarada como uma via de resolução de problemas e no âmbito dos quais a supervisão é quase inexistente (Holt \& Espelage, 2007) - utilizam estratégias de intimidação e de coerção, subjugando e inferiorizando as vítimas. Os adolescentes de sexo masculino, independentemente da sua orientação sexual, apresentam uma maior probabilidade do que as adolescentes de sexo feminino de se envolver em comportamentos de bullying homofóbico (Poteat \& DiGiovanni, 2010), como forma de afirmação da orientação sexual dominante - a heterossexual -, e de repúdio das masculinidades consideradas desviantes (Espelage et al., 2018; Herek, 2000).

Também o contexto cultural e o ambiente escolar parecem funcionar como fatores de risco para a prática do bullying homofóbico. Espelage e Swearer (2010) analisaram o fenómeno a partir de um prisma ecológico, advogando que o mesmo é o reflexo das relações estabelecidas pelas pessoas e pelos grupos nos contextos familiar, grupal, escolar e comunitário, espelhando, por sua vez, as normas sociais vigentes. Quando estas estão alinhadas com crenças de género conservadoras, a aceitação da diversidade sexual encontra fortes resistências. A noção de heterossexualidade compulsória está, pois, intimamente ligada às crenças e expectativas de género (Costa \& Davies, 2012), perpassando o modo como as relações sociais de género são estabelecidas. Estas, aqui entendidas como relações entre pessoas, grupos e comunidades fundadas no pressuposto das assimetrias de género e, subsequentemente, no seu diferencial de poder simbólico (Nogueira, 2001; Scott, 1998) desempenham um papel determinante na regulação das normas. Para Hong e Gabarino (2012), os valores heteronormativos podem estimular o preconceito e a discriminação contra pessoas LGBT. 0 bullying homofóbico inclui dinâmicas de poder (Espelage, Basile, \& Hamburger, 2015), constituindo-se também como uma expressão da violência de género, na medida em que o género é um sistema patriarcal e heteronormativo que constrange as identidades dos grupos socialmente mais vulneráveis, nomeadamente das mulheres e das pessoas LGBT (Rosa et al., 2018; Utrilla, García, \& Yáñez, 2018).

Sendo um fenómeno tendencialmente grupal, em ambiente escolar a indiferença do grupo de pares aumenta o potencial de risco para o bullying homofóbico (Poteat \& Vecho, 2016), ficando as vítimas LGBT especialmente mais fragilizadas (António, Guerra, \& Moleiro, 2019). Em contrapartida, os/as denominados/as bystanders, que funcionam como espectadores/as, podem, quando ativos/as, constituirse como um dos mais determinantes fatores protetores (Poteat, \& Vecho, 2016).

\section{Evidências empíricas sobre o bullying homofóbico}

Ainda que nos últimos anos os estudos nacionais e internacionais tenham vindo a traçar um retrato muito preocupante em termos da prevalência do bullying homofóbico sofrido pelos/as jovens - estudos como o de Poteat e Espelage (2005) revelam que 92\% das pessoas LGBT já foram vítimas de comportamentos homofóbicos, $84 \%$ sujeitas a ofensas verbais e $83 \%$ expostas a insultos, ameaças, violência física e sexual - as estatísticas não revelam seguramente a verdadeira dimensão do problema. Tal como sucede com outras formas de violência contra pessoas LGBT (Moleiro, Pinto, Oliveira, \& Santos, 2016), o bullying homofóbico tende a não ser denunciado, estimando-se que as cifras conhecidas não correspondam às reais, mas apenas a uma parcela dos crimes efetivamente cometidos. 
De acordo com os resultados de um inquérito sobre a discriminação e o discurso de ódio contra as pessoas LGBT em todos os Estados-Membros da União Europeia ( $\mathrm{N}=93000)$, realizado pela Agência Europeia dos Direitos Fundamentais em 2012 (FRA, 2014), uma percentagem de cerca de 50\% dos/as inquiridos/as afirmou ter-se sentido discriminada ou assediada em função da sua orientação sexual. As mulheres lésbicas (55\%), os/as inquiridos/as mais jovens (com idades compreendidas entre os 18 e os 24 anos) (57\%) e os/as inquiridos/as com menos rendimentos (52\%) foram aqueles/as que mais experiências de discriminação relataram. Os/As inquiridos/as oriundos/as da Lituânia (31\%), da Roménia (30\%) e de Portugal (29\%) sentiram-se cerca de três vezes mais discriminados/as do que os/as da Holanda (8\%), da Dinamarca (10\%) e da Bélgica (11\%). Sessenta por cento dos/as jovens LGBT foram alvo de comentários ou comportamentos negativos na escola por serem LGBT, sendo que mais de $80 \%$ testemunharam um/a colega de escola ser vítima de atitudes ou ações homofóbicas. Os dados indicam também que até aos 18 anos, dois em cada três jovens LGBT, maioritariamente homens gays e bissexuais, esconderam ou disfarçaram a sua orientação sexual na escola. Vinte e seis por cento de todos/as os/as inquiridos/as afirmaram ter sido física ou sexualmente agredidos/as ou ameaçados/as nos últimos 5 anos e 10\% nos últimos 12 meses anteriores ao inquérito. Destes/as, 59\% pensavam ter sido vitimados/as por serem LGBT. Assim, no cômputo geral, 6 \% de todos/as os/as inquiridos/as foram física ou sexualmente agredidos/as ou ameaçados/as por serem LGBT.

Um estudo recente, conduzido pela mesma Agência (FRA, 2016), revela que os/as profissionais que trabalham nas escolas estão conscientes da discriminação baseada na orientação sexual e na identidade de género, a qual pode variar desde o abuso verbal ao bullying severo.

Os dados do Observatório de Educação LGBT (Paulos, 2014), uma estrutura da Associação de jovens LGBTI e apoiantes da rede ex aequo que regista situações de discriminação em função da orientação sexual e da identidade de género ocorridas em estabelecimentos escolares em Portugal, mostram que a maior concentração de denúncias se situa nas faixas etárias da adolescência e do início da vida adulta (80\%), com 45\% das vítimas entre os 16 e 18 anos. Quarenta por cento das denúncias reportam-se à área geográfica de Lisboa e $20 \%$, respetivamente, às áreas do Porto e Setúbal. A grande maioria das situações ocorreu no ensino secundário, atingindo rapazes e raparigas de forma mais ou menos proporcional. 0 tipo de violência que mais sobressai é o verbal, seguido do psicológico e do físico. As agressões ocorrem, em $60 \%$ dos casos, mais de cinco vezes.

O Observatório da Discriminação em função da Orientação Sexual e da Identidade de Género, da Associação ILGA Portugal, que se destina a registar os crimes de ódio contra pessoas LGBT, recebeu 179 denúncias em 2016, 55.31\% das quais efetuadas pelas próprias vítimas (ILGA, 2016). Dos casos reportados, maioritariamente em Lisboa, 16.15\% tiveram lugar na escola, no ensino básico, secundário ou superior. A faixa etária mais afetada é a dos 18 aos 24 anos de idade (34.12\%), seguida da dos 25 aos 34 anos (21.76\%) e da dos/as menores de 18 anos (17.06\%). Cerca de cinquenta por cento das vítimas identificaram-se como homens e $25.29 \%$ como mulheres. 0 tipo de violência mais prevalente é o verbal e psicológico - insultos ou ameaças, em forma oral ou escrita (55.9\%), seguido do bullying (10.56\%). De destacar que nas situações de bullying, quer as vítimas, quer os/as bullies, se situam nas faixas etárias mais jovens.

Os resultados anteriormente descritos vão no mesmo sentido das conclusões do estudo de António e colaboradores/as, realizado em 2012, no contexto do qual se verificou que $42 \%$ dos/as jovens já tinham sido intimidados/as, insultados/as ou agredidos/as por serem homossexuais ou bissexuais e que 67\% já tinham testemunhado comportamentos homofóbicos. Os rapazes são mais frequentemente vítimas de bullying homofóbico do que as raparigas e a violência mais praticada é a psicológica. A maioria das agressões (28\%) ocorreu no recinto escolar, não tendo sido aplicada, posteriormente, nenhuma sanção ao/à agressor/a. Trinta e dois por cento dos/as jovens que assistiram à violência nada fizeram, $22 \%$ riram-se e apenas $17 \%$ intervieram, pedindo ao/à agressor/a para parar.

Também a investigação de Rodrigues e colegas (2016) constatou que os rapazes são mais vitimados do que as raparigas, silenciando ambos, geralmente, a vitimização sofrida. Tal silenciamento deve-se, entre outros fatores, ao receio da rejeição e do estigma. Mais recentemente, um estudo de Santos, Silva e Menezes (2017), cujo objetivo foi explorar as representações e as experiências de estudantes do ensino secundário sobre bullying homofóbico, em 12 escolas públicas do norte de Portugal, veio chamar a atenção para a necessidade de se auscultarem os processos de construção da masculinidade hegemónica, os quais são influenciados pelos usos da linguagem quotidiana, onde o insulto homofóbico generalizado surge como instrumento regulador e disciplinar em situações de desafio à ordem de género (Connell, 2005).

Os últimos dados do Index da Educação Inclusiva LGBTQI da Internacional Lesbian, Gay, Bisexual, Transgender, Queer \& Intersex Youth and Student Organisation (IGLYO) (Ávila, 2018) mostram que Portugal ocupa o 15. - lugar do ranking europeu, com uma classificação de 54.5 em 100, dispondo de um 
enquadramento legal relativamente inclusivo, o qual carece ainda de medidas concretas de implementação que garantam a segurança e a inclusão no espaço escolar.

Também os resultados do Estudo Nacional sobre o Ambiente Escolar (ENAE), promovido pela ILGA Portugal (2018), em parceria com o ISCTE e a Universidade do Porto, evidenciam que os/as jovens LGBTI não se sentem confortáveis e em segurança nas suas escolas por serem alvo de insultos e atitudes discriminatórias frequentes, o que leva a que cerca de um quarto destes/as evite frequentar espaços como os balneários, casas de banho ou aulas de Educação Física. Verifica-se, ainda, uma probabilidade de absentismo escolar quatro vezes superior à dos/as jovens que não são vítimas de discriminação. Outros fatores, como a perceção de falta de apoio recebido por parte do pessoal docente e não docente, a insuficiência de recursos e a inexistência de políticas anti-bullying, parecem contribuir para o distanciamento e para os baixos níveis de sentimento de pertença destes/as jovens em relação à escola. Simultaneamente, os resultados revelam que parece existir um maior sentido de segurança e pertença nas escolas onde existem ações positivas acerca das temáticas LGBTI. Assim, o estudo vem realçar a necessidade de se adotarem estratégias de intervenção mais ativas no combate à homofobia e transfobia em contexto escolar, devendo estas incluir os diferentes agentes de atuação na comunidade escolar (ILGA, 2018).

Procurando colmatar a escassez de estudos sobre o bullying homofóbico no ensino superior português, a presente investigação procurou caracterizar as crenças e as práticas de estudantes universitários/as, analisando a extensão e a expressão do fenómeno. Foram seus objetivos específicos: a) conhecer as crenças dos/as participantes sobre as relações sociais de género; b) conhecer as crenças dos/as participantes sobre as pessoas lésbicas e gays; c) explorar a prevalência do bullying homofóbico; d) analisar a relação entre as crenças de género e o sexo; e) analisar a relação entre as crenças sobre a orientação sexual gay e lésbica, o sexo, a área de formação académica e a idade dos/as participantes; f) analisar a relação entre as crenças sobre a orientação sexual gay e lésbica e as crenças de género; e g) analisar a relação entre a prática de comportamentos violentos contra pessoas gays e lésbicas, as crenças sobre a orientação sexual gay e lésbica e as crenças de género.

\section{MÉTODO}

\section{Participantes}

O presente estudo contou com a participação de 369 estudantes de instituições de Ensino Superior da zona norte do país, com idades compreendidas entre os 18 e os 61 anos (M=21.49, DP=5.463). Do total dos/as participantes, 282 (76.4\%) identificaram-se como sendo do sexo feminino e 84 (22.8\%) como sendo do sexo masculino. Relativamente à orientação sexual dos/as participantes, 171 (46.3\%) não responderam à questão colocada, 180 (48.8\%) identificaram-se como sendo heterossexuais e 18 (4.9\%) como não-heterossexuais.

Duzentos e cinquenta e nove (70.2\%) dos/as estudantes frequentavam Licenciaturas da área de Direito, Ciências Sociais e Serviços, sendo que os/as restantes 110 (29.8\%) participantes provinham de áreas como Educação Física, Desporto e Artes do Espetáculo, Ciências da Educação, Tecnologias, entre outras (ver Tabela 1). A maioria (95.5\%) dos/as estudantes era de nacionalidade portuguesa, 22 (6.0\%) participantes identificaram-se como estudantes-trabalhadores/as e mais de metade (59.4\%) frequentava instituições de ensino privadas. Com vista a minimizar a possibilidade de contacto prévio dos/as estudantes com a temática, em contexto de sala de aula, todos/as os/as participantes frequentavam o primeiro ano das respetivas Licenciaturas.

\section{Instrumentos}

Para a recolha dos dados foram administrados uma ficha sociodemográfica e três instrumentos construídos de raiz para esta investigação, com base em estudos prévios, referenciados na primeira parte deste artigo (e.g., Rodrigues et al., 2016; Santos, Silva, \& Menezes, 2017), e em Literatura especializada.

Inventário sobre Crenças de Género (ICG). O ICG é constituído por 24 itens numa escala de Likert de 3 pontos com a seguintes opções de resposta: "1 - Não Concordo", “2 - Não concordo, nem discordo" e "3 Concordo". O seu objetivo é avaliar as crenças dos/as participantes sobre as relações sociais de género. São apresentadas 24 afirmações, 19 delas estruturadas positivamente no sentido de que uma resposta "Concordo" dê indicação de uma crença de género mais conservadora (e.g., "CG01 A família deve ser a prioridade das mulheres", “CG06 Se as mulheres não trabalhassem fora de casa, as crianças seriam melhor educadas"). As restantes 5 afirmações estão estruturadas negativamente no sentido em que indivíduos com crenças de género menos conservadoras responderão com “Concordo" a estas questões (e.g., "CG04 Os homens podem ser tão bons pais quanto as mulheres boas mães", e "CG09 Homens e mulheres devem 
partilhar as tarefas domésticas"). Após a inversão destes 5 itens, é produzido um score ICG com a soma de todas as respostas. Desta forma, valores mais altos do score ICG revelam crenças mais conservadoras. A análise de consistência interna do ICG revelou-se razoável $(\alpha=0.759)$.

Tabela 1. Características demográficas dos/as participantes

\begin{tabular}{|c|c|c|}
\hline & $\mathbf{n}$ & $\%$ \\
\hline \multicolumn{3}{|l|}{ Sexo } \\
\hline Feminino & 282 & 76.4 \\
\hline Masculino & 84 & 22.8 \\
\hline Outro & 2 & 0.5 \\
\hline \multicolumn{3}{|l|}{ Orientação Sexual } \\
\hline Heterossexual & 180 & 48.8 \\
\hline Não heterossexual & 18 & 4.9 \\
\hline Sem resposta & 171 & 46.3 \\
\hline \multicolumn{3}{|l|}{ Classes etárias } \\
\hline $18-25$ anos & 331 & 89.7 \\
\hline $26-35$ anos & 21 & 5.7 \\
\hline Mais de 35 anos & 15 & 4.1 \\
\hline \multicolumn{3}{|l|}{ Nacionalidade } \\
\hline Portuguesa & 191 & 51.8 \\
\hline Outra & 9 & 2.4 \\
\hline \multicolumn{3}{|l|}{ Instituição } \\
\hline Privada & 256 & 59.4 \\
\hline Pública & 113 & 30.6 \\
\hline \multicolumn{3}{|l|}{ Área de formação } \\
\hline Direito, Ciências Sociais e Serviços & 259 & 70.2 \\
\hline Educação Física, Desporto e Artes do Espetáculo & 28 & 7.6 \\
\hline Ciências da Educação & 27 & 7.3 \\
\hline Tecnologias & 22 & 6.0 \\
\hline Saúde & 15 & 4.1 \\
\hline Humanidades, Secretariado e Tradução & 15 & 4.1 \\
\hline Economia, Gestão e Contabilidade & 2 & 0.5 \\
\hline Arquitetura, Artes Plásticas e Design & 1 & 0.3 \\
\hline \multicolumn{3}{|l|}{ Situação atual } \\
\hline Estudante & 147 & 39.8 \\
\hline Estudante trabalhador/a & 22 & 6.0 \\
\hline
\end{tabular}

Inventário de crenças sobre a orientação sexual gay e lésbica - Ensino Superior (ICOLG-ES). 0 ICOLG-ES é constituído por 25 itens numa escala de Likert de 3 pontos com as seguintes opções de resposta: "1 - Não concordo", "2 - Não concordo, nem discordo" e "3 - Concordo". O seu objetivo é avaliar as crenças que os/as participantes exibem sobre as pessoas lésbicas e gays. Das 25 afirmações apresentadas, 20 apresentam uma estrutura positiva no sentido em que uma resposta "Concordo" indica uma crença mais conservadora (e.g. "COLG01 Incomoda-me ver dois homens a beijar-se", ou "COLG06 A homossexualidade e o lesbianismo são uma doença"). As restantes 5 afirmações apresentam-se com uma estrutura negativa (e.g. "COLG07 Os casais homossexuais e lésbicos devem poder adotar crianças da mesma forma que os casais heterossexuais", ou "COLG11 A orientação sexual das pessoas é uma caraterística como tantas outras"). Após a inversão destes 5 itens, é produzido um score COLG em que valores mais altos refletem crenças sobre pessoas lésbicas e gays mais conservadoras. A análise de consistência interna do ICOLG-ES revelou-se razoável $(\alpha=0.799)$.

Inventário sobre Práticas Violentas contra Lésbicas e Gays - Ensino Superior (IPVLG-ES). O IPVLGES apresenta uma listagem de 12 comportamentos de violência que os/as participantes possam já ter 
presenciado, praticado e/ou vivenciado por ser (ou por pensar que é) gay ou lésbica. Deste modo, e de acordo com a experiência de cada um/a, selecionam-se as opções que melhor descrevem a situação: "Nunca aconteceu", "Já sofri", "Já fiz" e "Já observei", sendo que estas opções são mutuamente selecionáveis. Todas as questões indicam que o comportamento se deve a ser-se (ou a pensar que se é) gay ou lésbica (e.g. "PVLG02 - Caluniar, difamar, falar mal, por ser (ou por pensar que é) gay ou lésbica", "PVLG07 - Bater, empurrar, ferir, por ser (ou por pensar que é) gay ou lésbica"). Para cada participante é contabilizado o número de respostas "Já fiz" a cada um dos 12 comportamentos apresentados, produzindo uma variável que representa a proporção de violência praticada. As respostas a estes 12 comportamentos permitem também classificar cada um/a dos/as participantes como sendo vítima e/ou agressor/a, caso estes/as tenham respondido a algum dos itens com "Já fiz" e/ou "Já sofri". Sendo objetivo desta investigação identificar os/as participantes vítimas e/ou agressores/as, a contabilização das respostas "Já observei" não foi utilizada para uma descrição dos possíveis bystanders.

\section{Procedimentos}

Por forma a realizar o presente estudo foram dirigidos inicialmente pedidos de autorização às Direções das instituições de Ensino Superior onde se efetuou a recolha dos dados. Depois de obtidas a autorizações foram contactados/as os/as Diretores/as de Departamento e respetivos Coordenadores/as das Licenciaturas no sentido de solicitar a colaboração dos/as mesmos/as. Findo este procedimento, foram analisados os horários das turmas de 1. - ano e contactados/as os/as professores/as que lecionavam unidades curriculares obrigatórias, para que pudessem ceder parte das suas aulas para a administração dos instrumentos. Depois de negociados os horários da recolha, foram abordadas presencialmente as turmas a fim de se explicar os objetivos do estudo e requerer a participação dos/as estudantes. A todos/as foi entregue um consentimento informado e explicadas as instruções do preenchimento, o qual foi feito individualmente, num tempo médio de cerca de 30 minutos. Estiveram presentes, em todos os momentos da recolha, duas investigadoras com formação em Psicologia e Criminologia.

O presente estudo foi aprovado pela Comissão de Ética da instituição de ensino de proveniência das investigadoras responsáveis. Foi garantida a confidencialidade e anonimato dos dados utilizados ao longo de todo o estudo. 0 tratamento estatístico foi levado a cabo com recurso ao IBM SPSS versão 25.

\section{RESULTADOS}

\section{Análise descritiva}

Uma primeira análise dos resultados incidiu sobre os instrumentos aplicados de forma a obter uma caracterização geral e descritiva da amostra. Serão apresentados os dados cujos valores se afiguram mais expressivos do ponto de vista dos objetivos da investigação.

Crenças sobre as relações sociais de género. No que diz respeito às afirmações que compõem o ICG, observou-se que $8.3 \%$ dos homens concordaram com a afirmação de que as mulheres que investem mais na carreira do que na família não são nem boas mães, nem boas companheiras; uma percentagem muito semelhante (7.1\%) de homens concordou que o sonho de qualquer mulher é casar. Acresce que $12 \%$ dos homens concordaram que os homens devem chefiar a família e $7.4 \%$ admitiram que estes são mais competentes do que as mulheres para cargos de liderança. Para além disso, 8.3\% dos homens concordaram que meninos e meninas devem ser educados de forma diferente. Relativamente a situações de violência doméstica, $21.4 \%$ dos homens e $17 \%$ das mulheres concordaram com a afirmação "Algumas situações de violência doméstica são provocadas pelas mulheres" e $11.9 \%$ dos homens concordaram que as mulheres que mantêm relações amorosas violentas são masoquistas. Das mulheres, $4.6 \%$ entenderam que é gratificante para elas ouvir piropos, enquanto que $14.3 \%$ dos homens concordaram que o ciúme é uma prova de amor. Uma parte considerável dos homens (38.1\%) e $27.8 \%$ das mulheres concordaram que as mulheres são mais sensíveis do que os homens e $21.4 \%$ dos homens e $16.4 \%$ das mulheres acharam que as mulheres não são tão violentas quanto os homens.

Crenças sobre pessoas lésbicas e gays. Considerando as afirmações que compõem o ICLG-ES, 48.8\% dos homens concordaram não se sentir incomodados por ver dois homens a beijar-se, mas $9.6 \%$ concordaram que estar perto de um gay os deixava desconfortáveis. $12 \%$ referiram sentir-se incomodados por ver duas mulheres a beijar-se, enquanto $17.9 \%$ dos homens e $21.6 \%$ das mulheres concordaram que os gays e as lésbicas costumam ser rejeitados/as pelos/as amigos/as. $20.2 \%$ dos homens discordaram que não lhes interessa saber se os amigos são gays ou as amigas lésbicas. Relativamente à adoção de crianças por casais de pessoas do mesmo sexo, 14.3\% dos homens 
defenderam que estes, ao contrário dos casais de pessoas de sexo diferente, não devem poder adotar crianças. Verificou-se ainda que $10.7 \%$ dos homens e $8.5 \%$ das mulheres concordaram que os gays são homens mais sensíveis; $8.3 \%$ dos homens concordaram que os gays são mais vaidosos do que os homens heterossexuais e $9.5 \%$ dos homens e $4.3 \%$ das mulheres afirmaram que as lésbicas são mais masculinas do que as mulheres heterossexuais. Ressaltou ainda que $14.3 \%$ dos homens e $15 \%$ das mulheres concordaram que os gays e as lésbicas podem escolher ser heterossexuais.

Prevalência do bullying homofóbico. Explorando a prevalência do bullying homofóbico com recurso ao IPVLG-ES, e considerando os comportamentos de violência que os/as participantes possam já ter presenciado, praticado e/ou vivenciado por ser (ou pensar que é) gay ou lésbica, verificou-se que 3.6\% dos homens e $4.3 \%$ das mulheres já sofreram, e $10.8 \%$ dos homens e $6.1 \%$ mulheres já fizeram insultos, piadas, gozaram, humilharam e/ou envergonharam (Tabela 2). Verificou-se também que $3.6 \%$ dos homens e 3.2\% das mulheres já sofreram, e $6 \%$ dos homens e $1.1 \%$ das mulheres já fizeram calúnias, difamações, falar mal, por ser (ou pensar que é) gay ou lésbica. A par destas situações, $3.6 \%$ dos homens já foram ignorados, isolados, excluídos do grupo, por ser (ou por pensar que é) gay, e $2.4 \%$ dos homens e $1.4 \%$ das mulheres admitiram já o ter feito.

No que concerne às ameaças, a análise das frequências das respostas revelou que $2.4 \%$ dos homens já sofreram e $3.6 \%$ dos homens e $7.1 \%$ das mulheres já observaram ameaças de morte, por ser (ou por pensar que é) gay ou lésbica. Observou-se ainda que $2.4 \%$ dos homens e $0.7 \%$ das mulheres já sofreram, e $0.4 \%$ das mulheres já fizeram ameaças de divulgação pública da orientação sexual, por ser (ou por pensar que é) gay ou lésbica. 3.6\% dos homens e $1.1 \%$ das mulheres já sofreram, e $1.2 \%$ dos homens e $0.7 \%$ das mulheres já fizeram chantagens, ameaças e propagação de boatos através das tecnologias de informação e comunicação (e.g., WhatsApp, Instagram, Facebook, Messenger) por ser (ou por pensar que é) gay ou lésbica. Também $2.4 \%$ dos homens já sofreram e $0.4 \%$ das mulheres admitiram já ter perseguido, vigiado, controlado alguém, por ser (ou por pensar que é) gay ou lésbica.

No que concerne à violência física, $2.5 \%$ dos homens já sofreram e $0.4 \%$ das mulheres já praticaram agressões como bater, empurrar, ferir, por ser (ou por pensar que é) gay ou lésbica. Acresce que $1.2 \%$ dos homens já sofreram, $1.2 \%$ dos homens e $0.4 \%$ das mulheres já praticaram agressões físicas com necessidade de tratamento médico, por ser (ou por pensar que é) gay ou lésbica. Também $1.2 \%$ dos homens e $0.4 \%$ das mulheres já sofreram, e $1.2 \%$ dos homens e $4.3 \%$ das mulheres já observaram alguém a tocar, ou agredir nos órgãos genitais, por ser (ou pensar que é) gay ou lésbica, e 1.2\% dos homens já sofreram e 1.8\% das mulheres já observaram alguém a obrigar outrem a ter comportamentos sexuais não desejados (e.g., forçar a ter relações sexuais de natureza oral, anal, coital, com outra/s pessoa/s), por ser (ou por pensar que é) gay ou lésbica.

Tabela 2. Práticas de violência por ser (ou pensar que é) gay ou lésbica

\begin{tabular}{lcccc}
\hline & \multicolumn{2}{c}{ Homens (\%) } & \multicolumn{2}{c}{ Mulheres (\%) } \\
\cline { 2 - 5 } & Sofri & Fiz & Sofri & Fiz \\
\hline Insultar, fazer piadas, gozar, humilhar, envergonhar & 3.6 & 10.8 & 4.3 & 6.1 \\
Caluniar, difamar, falar mal & 3.6 & 6.0 & 3.2 & 1.1 \\
Ignorar, isolar, não incluir no grupo & 3.6 & 2.4 & 1.1 & 1.4 \\
Estragar ou roubar coisas & 2.4 & 0.0 & 0.0 & 0.4 \\
Ameaçar de morte & 2.4 & 0.0 & 0.0 & 0.0 \\
Ameaçar divulgar publicamente a orientação sexual & 2.4 & 0.0 & 0.7 & 0.4 \\
Chantagear, ameaçar, espalhar boatos através das TIC & 3.6 & 1.2 & 1.1 & 0.7 \\
Perseguir, vigiar, controlar & 2.5 & 0.0 & 0.0 & 0.4 \\
Bater, empurrar, ferir & 2.5 & 0.0 & 0.0 & 0.4 \\
Agredir fisicamente com necessidade de tratamento & 1.2 & 1.2 & 0.0 & 0.4 \\
médico & 1.2 & 0.0 & 0.4 & 0.0 \\
Tocar, agredir nos órgãos genitais & 1.2 & 0.0 & 0.0 & 0.0 \\
Obrigar a ter comportamentos sexuais não desejados & & 0.0 \\
\hline
\end{tabular}

\section{Análise das relações}

Relação entre as crenças sociais de género e o sexo dos/as participantes. Para melhor conhecer as crenças dos/as participantes sobre as relações sociais de género, foram realizados testes $t$ para 
comparação de médias do score do ICG entre os grupos feminino e masculino. Lembrando que o ICG reflete uma visão mais ou menos conservadora consoante o score neste Inventário é maior ou menor, respetivamente, verificou-se que os homens revelaram crenças mais conservadoras do que as mulheres $(t(93.212)=-4.171, p<.001)$ (cf. Tabela 3$)$.

Tabela 3. Diferenças de médias

\begin{tabular}{|c|c|c|c|c|}
\hline & $\mathbf{M}$ & DP & $t$ & $\mathbf{F}$ \\
\hline \multicolumn{5}{|l|}{ Crenças de género } \\
\hline Feminino & 29.8 & 4.175 & \multirow{2}{*}{$-4.171^{* * *}$} & \\
\hline Masculino & 32.8 & 5.765 & & \\
\hline Pratica & 33.5 & 7.830 & \multirow{2}{*}{$-1.790^{*}$} & \\
\hline Não pratica & 30.3 & 4.486 & & \\
\hline \multicolumn{5}{|l|}{ Crenças LG } \\
\hline Feminino & 31.3 & 4.588 & \multirow{2}{*}{$-4.908^{* * *}$} & \\
\hline Masculino & 35.3 & 6.908 & & \\
\hline Direito, Ciências Sociais e Serviços & 31.7 & 4.964 & \multirow{2}{*}{$-3.375^{* *}$} & \\
\hline Outras áreas & 33.9 & 6.750 & & \\
\hline $18-25$ anos & 30.4 & 4.584 & & \multirow{3}{*}{2.959} \\
\hline $26-35$ anos & 29.9 & 6.598 & & \\
\hline Mais de 35 anos & 31.1 & 4.269 & & \\
\hline Pratica & 37.81 & 7.801 & \multirow{2}{*}{$-3.366^{* *}$} & \\
\hline Não pratica & 32.00 & 5.291 & & \\
\hline \multicolumn{5}{|l|}{ Prática de violência } \\
\hline Feminino & 0.005 & 0.042 & \multirow{2}{*}{$-2.021^{* *}$} & \\
\hline Masculino & 0.018 & 0.053 & & \\
\hline
\end{tabular}

Nota. ${ }^{*}$ p-valor $<.05 ;{ }^{* *}$ p-valor $<.01 ;{ }^{* * *}$ p-valor $<.001$

Relação entre as crenças sobre a orientação sexual gay e lésbica, o sexo, a área de formação académica e a idade dos/as participantes. Com o objetivo de explorar a relação entre as crenças sobre pessoas lésbicas e gays, o sexo, a área de formação académica e a idade dos/as participantes, aplicaram-se testes $t$ para comparação de médias. Tendo em conta a formação académica dos/as participantes, e dada a variedade de cursos presentes na amostra, optou-se por agrupá-los/as em duas áreas: uma com os cursos da área de Direito, Ciências Sociais e Serviços, outra com as restantes. Esta divisão teve em conta as características sociais e humanas envolvidas nos cursos das áreas de Direito, Ciências Sociais e Serviços, bem como a alusão a estas temáticas nestas áreas de estudo comparativamente com as restantes. No que à idade diz respeito, a análise teve em conta três grupos etários divididos em idades iguais ou inferiores a 25 anos; 26 a 34 anos; e maiores de 35 anos, adotando o critério usado no Observatório da Discriminação em função da Orientação Sexual e da Identidade de Género, da ILGA Portugal (ILGA, 2016).

Valores mais altos no score do ICLG-ES revelam crenças mais conservadoras. Deste modo, verificou-se que os homens revelaram crenças mais conservadoras do que as mulheres $(t(102.046)=-$ $4.908, p<.001$ ). No que à formação académica diz respeito, os/as estudantes das Licenciaturas das áreas de Direito, Ciências Sociais e Serviços revelaram crenças menos conservadoras do que os/as estudantes das outras áreas $(t(151.4)=-2.982, p=0.002)$. Quanto à idade, e através de uma Análise de Variância, verifica-se não haver diferenças significativas no que respeita às crenças sobre a orientação sexual de pessoas lésbicas e gays $(F(2)=2.959, p=0.053$ ) (cf. Tabela 3 ).

Relação entre as crenças sobre a orientação sexual gay e lésbica e as crenças de género. 0 ICG reflete uma visão mais ou menos conservadora consoante o score neste Inventário é maior ou menor, respetivamente. Neste sentido, ao explorar a relação entre as crenças sobre a orientação sexual gay e lésbica e as crenças de género, foi identificada uma correlação moderada positiva e estatisticamente significativa, indicando que as pessoas que revelam crenças sobre a orientação sexual mais conservadoras são aquelas que também revelam crenças de género mais conservadoras $(r=0.423, p<$ 0.001). 
Relação entre a prática de comportamentos violentos contra pessoas gays e lésbicas, as crenças sobre a orientação sexual gay e lésbica e as crenças de género. De forma a estudar a relação entre a prática de comportamentos violentos contra pessoas gays e lésbicas, as crenças sobre a orientação sexual gay e lésbica e as crenças de género, foram identificados dois grupos: os que praticam e os que não praticam comportamentos violentos. A distinção entre os dois grupos foi feita com base nas respostas às questões do IPVLG-ES. Em consequência, verificou-se que os indivíduos que praticam comportamentos violentos contra pessoas gays e lésbicas apresentam crenças mais conservadoras sobre a orientação sexual gay e lésbica $(t(21.176)=-3.366, p=0.002)$. Igual conclusão se obteve relativamente às crenças de género nestes dois grupos $(t(19.768)=-0.1 .790, p=0.045)$. A avaliação da prática de violência contra pessoas gays e lésbicas nos dois sexos foi feita usando um índice de violência obtido com base nas respostas às questões ao Inventário sobre práticas violentas contra pessoas lésbicas e gays. Este índice reflete a proporção de respostas "Já fiz" às questões do Inventário. Observaram-se diferenças estatisticamente significativas da prática de violência entre os grupos feminino e masculino $(t(115.471)=$ -2.021, $p=0.046$ ), nomeadamente valores de prática de violência superiores no grupo masculino (cf. Tabela 3).

\section{DISCUSSÃO E CONCLUSÕES}

Esta investigação teve como objetivo geral caracterizar as crenças e as práticas de estudantes do Ensino Superior em Portugal, de ambos os sexos, no que respeita ao bullying homofóbico, analisando a extensão e a expressão do fenómeno.

Apesar de no país se ter assistido, nos últimos anos, ao reconhecimento de direitos fundamentais das pessoas LGBT, o bullying homofóbico continua a manifestar-se em contexto educativo, como apontam os resultados dos vários estudos nacionais e internacionais que quer a academia (e.g., Rodrigues et al., 2016), quer a sociedade civil (e.g., ILGA, 2016), têm vindo a produzir.

Da análise dos dados recolhidos conclui-se que existem pessoas que já sofreram alguma forma de violência por serem identificadas como gays ou lésbicas. Os homens são aqueles que apresentam taxas mais elevadas quer de vitimação, quer de perpetração, sugerindo que o crivo da masculinidade hegemónica opera quer no sentido de uma maior adesão às normas de género por parte destes, quer no sentido de uma maior penalização daqueles que as contrariam. Como referem Costa e Davies (2012), os homens tendem a ser socializados à luz de normas de género mais rígidas e restritivas do que as mulheres, sendo esta socialização, em si mesma, homofóbica e sexista. É expectável, portanto, que os homens sejam mais defensivos do que as mulheres relativamente a quem desafia as normas de género. Com efeito, o facto dos gays contrariarem a ordem de género estabelecida (Connell, 2005), mais do que as lésbicas, torna-os mais suscetíveis aos crimes de ódio (Plummer, 2016), tal como atestam os dados empíricos e estatísticos disponíveis sobre a discriminação e a violência com base na orientação sexual (e.g., ILGA, 2016; Poteat \& DiGiovanni, 2010).

Também à semelhança de outros estudos (e.g., Espelage et al., 2008; Moleiro et al., 2016), a violência psicológica é o tipo de violência mais praticado, manifestando-se através de insultos, piadas, gozo, humilhação e atos que visam envergonhar as vítimas. Embora a violência física e sexual sejam menos prevalentes, as condutas sofridas, perpetradas ou observadas neste estudo revestem-se de especial gravidade. De salientar o facto de um dos homens da amostra ter sido obrigado a ter comportamentos sexuais não desejados por ter sido identificado como gay, sendo que cinco mulheres afirmaram já ter observado tais comportamentos.

Um dos dados que mais sobressai nesta investigação é precisamente a percentagem de pessoas que admite já ter observado a prática de bullying homofóbico. Alguns estudos (e.g., Hawkins, Pepler, \& Craig, 2001) referem que na grande maioria das situações esta prática é testemunhada por terceiros que, condenando-a, assumem geralmente perante ela uma postura de passividade (Smith, Twemlow, \& Hoover, 1999). Assim, os gays e as lésbicas expostos/as a violência tendem a ser menos ajudados/as do que as pessoas heterossexuais, inclusivamente por pessoas estranhas (Gabriel \& Banse, 2006), o que os/as deixa numa condição de agravada vulnerabilidade. Ainda assim, as mulheres são, nestes casos, mais empáticas e apoiantes para com as vítimas, talvez por estarem mais atentas a situações de perigo (e.g., Rigby, 1997). Neste estudo, em concreto, são as mulheres que referem observar mais os comportamentos de bullying homofóbico.

A falta de suporte experienciada pelas vítimas realça a necessidade de lhes serem providenciados serviços de apoio especializado e mecanismos de resposta eficazes em ambiente escolar (ILGA, 2018), minimizando desse modo as consequências adversas da exposição à vitimação. Por outro lado, fica patente a necessidade de capacitar os/as bystanders para a denúncia, a intervenção e o encaminhamento, uma vez que o seu papel pode ser decisivo na prevenção e no combate ao bullying homofóbico (António, Guerra, \& Moleiro, 2018; Poteat \& Vecho, 2016). 
A par dos índices de violência sofrida, perpetrada e observada, os resultados evidenciam uma relação entre a prática de bullying homofóbico, as crenças sobre o género e as crenças sobre a orientação sexual gay e lésbica. Nesse sentido, são os/as estudantes que praticam mais comportamentos violentos contra pessoas lésbicas e gays, ou contra pessoas que presumem ter uma orientação sexual não heterossexual, os/as que exibem crenças sobre o género e sobre a orientação sexual gay e lésbica mais conservadoras. Estes resultados são, mais uma vez, especialmente expressivos no grupo dos homens, reforçando a ideia de que socialização de género parece ser mais determinante no sexo masculino do que no feminino no que às questões do bullying homofóbico diz respeito. De acordo com Walton (2005), o bullying é uma construção social e política enquadrada num sistema mais amplo de opressão social. Nessa ótica, nenhuma intervenção que tenha em vista preveni-lo ou combatê-lo pode ser levado a cabo sem o devido enquadramento sociopolítico, no âmbito do qual as questões de género têm que ser forçosamente consideradas, sobretudo se se perspetivar, como aqui se faz, o bullying homofóbico como uma expressão da violência de género.

De facto, os dados relativos às crenças de género patentes nesta investigação vêm sublinhar a necessidade de se adotar programas educativos orientados para a promoção da igualdade de género. Como ficou evidente, os papéis tradicionais de género continuam a ser valorizados por alguns e algumas estudantes, remetendo as mulheres para o espaço da família, onde sobressai a sua função de cuidadoras, e os homens para o espaço do trabalho, onde se destaca a sua função de líderes. Também sobre as relações de intimidade, proliferam os estereótipos. Uma percentagem bastante significativa de estudantes - cerca de $20 \%$ quer dos homens, quer das mulheres - concorda que algumas situações de violência doméstica são provocadas pelas mulheres e cerca de $14 \%$ dos homens concordam que o ciúme é uma prova de amor. Estas evidências são muitas vezes esgrimidas para legitimar o recurso à violência, desculpabilizando-se assim os agressores e culpabilizando-se as vítimas.

Ainda que persistam atitudes de discriminação e de violência contra pessoas LGBT, este estudo apresenta dados que sugerem atitudes genericamente positivas dos/as estudantes universitários/as face à orientação sexual. Como avançam, noutra investigação, Torres e colaboradores/as (2018), os/as jovens portugueses/as parecem estar cada vez mais abertos/as à mudança, defendendo menos do que as pessoas mais velhas os valores universalistas. Neste contexto, cerca de metade dos participantes homens (48.8\%) não se sente incomodado por ver dois homens a beijar-se e esta percentagem aumenta significativamente em relação às mulheres (80.1\%). Não obstante cerca de $10 \%$ dos homens terem referido que estar perto de um gay os deixava desconfortáveis, verifica-se uma maior consciencialização face à existência da homofobia e dos seus impactos, na medida em que os/as estudantes parecem compreender a rejeição a que os gays e as lésbicas costumam estar sujeitos/as. Adicionalmente, $60.7 \%$ dos homens não têm interesse em saber se os amigos são gays ou se as amigas são lésbicas concordando, em $59.5 \%$ dos casos, que as pessoas do mesmo sexo devem poder adotar crianças da mesma forma que os casais de sexo diferente.

São os/as estudantes das Licenciaturas das áreas do Direito, Ciências Sociais e Serviços aqueles/as que manifestam crenças menos conservadoras sobre a orientação gay e lésbica, o que pode espelhar uma maior abertura a questões de natureza social.

Do exposto, fica evidente a premência de serem desenvolvidas medidas e ações positivas acerca das temáticas LGBT, de modo a que o fenómeno possa ser reconhecido como um problema de Saúde Pública, clarificando-se os riscos associados e os seus efeitos e contribuindo-se para a sua erradicação. Parece, pois, ser fundamental que o conhecimento sobre a discriminação e a violência sobre pessoas LGBT possa ser disseminado no Ensino Superior, através da aposta no desenho e implementação de instrumentos/programas de formação, prevenção e proteção às vítimas. A Estratégia Nacional para a Igualdade e a Não Discriminação 2018-2030, que Portugal entretanto adotou, inclui um Plano de Ação para o Combate à Discriminação em razão da Orientação Sexual, Identidade e Expressão de Género e Características Sexuais onde as questões da eliminação de todas as formas de violência contra as mulheres, violência de género e violência doméstica, e da violência exercida contras as pessoas LGBTI assume especial relevância.

Tal como advogam Hong e Espelage (2012), o uso de uma metodologia ecológica, baseada em múltiplas metodologias de intervenção, pode avaliar e incrementar a resolução de problemas, a empatia e as competências sociais de vítimas, agressores e bystanders, mas também de escolas, vizinhanças e outros/as interlocutores/as. Nessa ótica, o desenvolvimento de programas de prevenção do bullying homofóbico com um enfoque ecológico poderia ser, simultaneamente, uma das vias possíveis de promoção da igualdade de género.

Como limitações da presente investigação, aponta-se o reduzido tamanho da amostra, o qual não permite a generalização dos resultados, bem como o facto de quase $80 \%$ da mesma ser do sexo feminino, não havendo por isso equilíbrio no que respeita à representação de cada um dos sexos. Apesar de ter sido 
avaliada a consistência interna dos instrumentos utilizados, estes ainda não foram validados, o que apresenta uma limitação desta investigação.

Para além do alargamento do estudo a outras regiões do país, a um mais significativo número de estudantes do Ensino Superior e a mais indivíduos do sexo masculino, seria interessante, em termos de investigação futura, escrutinar o papel dos/as bystanders na prática do bullying homofóbico, assim como na sua prevenção. Por forma a complementar alguns dos resultados obtidos e a melhor sustentar os programas de prevenção, a realização de estudos qualitativos com vítimas de bullying homofóbico, no sentido de aferir os significados e os impactos da vitimação do ponto de vista psicológico (e.g., saúde mental) e social (e.g., integração escolar, rendimento académico), seria fundamental. A validação dos instrumentos aqui utilizados será outra tarefa a levar a cabo em trabalhos futuros.

Por fim, este estudo ao permitir conhecer as crenças e as práticas dos/as estudantes universitários/as em Portugal sobre o bullying homofóbico, espera potenciar a construção de uma consciência social menos opressora e uma sociedade mais inclusiva em contexto académico.

\section{REFERÊNCIAS}

Adams, N., Cox, T., \& Dunstan, L. (2004). 'I Am the Hate that Dare Not Speak its Name': Dealing with homophobia in secondary schools. Educational Psychology in Practice, 20, 3. doi:10.1080/0266736042000251826

António, R., Guerra, R., \& Moleiro, C. (2018). Stay away or stay together? Social contagion, common identity, and bystanders' interventions in homophobic bullying episodes. Group Processes and Intergroup Relations. doi: 10.1177/1368430218782741

António, R., Pinto, T., Pereira, C., Farcas, D., \& Moleiro C. (2012). Bullying Homofóbico no Contexto escolar em Portugal. Psicologia, 26(1), 17-32.

Ávila, R. (2018). LGBTQI Inclusive Education Report. Brussels: IGLYO.

Bacon, L. A. (2011). Study of effective strategies, programs, and policies for school leaders in protecting lesbian, gay, bisexual, and transgender youth from peer victimization (Master Dissertation). Southern University, Georgia, EUA.

Connell, R. (2005). Masculinities (2nd Edition). Cambridge: Polity Press.

Costa, P., \& Davies, M. (2012). Portuguese Adolescents' Attitudes Toward Sexual Minorities: Transphobia, Homophobia, and Gender Role Beliefs. Journal of Homosexuality, 59, 1424-1442. doi: 10.1080/00918369.2012.724944

Espelage, D. L., Aragon, S. R., Birkett, M., \& Koenig, B. W. (2008). Homophobic teasing, psychological outcomes and sexual orientation among high school students: What influence do parents and schools have? School Psychology Review, 37(2), 202-216.

Espelage, D. L., Basile, K., \& Hamburger, M. (2015). Longitudinal Associations among Bullying, Homophobic Teasing, and Sexual Violence Perpetration among Middle School Students. Journal of interpersonal violence, 30(14), 2541-2561. doi:10.1177/0886260514553113

Espelage, D. L., \& Swearer, S. M. (2010). Bullying in North American Schools: A social-ecological perspective on prevention and intervention. New York: Routledge.

Espelage, D. L. et al. (2018). A literature review of protective factors associated with homophobic bullying and its consequences among children and adolescents. Aggression and Violent Behavior, 45, 98-110. doi: 10.1016/j.avb.2018.07.003

Ferreira, M. (2013). Os Jovens, a Escola e o Cyberbullying (Dissertação de Mestrado não publicada). Castelo Branco, Instituto Politécnico de Castelo Branco, Portugal.

Fonseca, P. M. (2015). Bullying e Cyberbullying: Estudo do Fenómeno em jovens estudantes do ensino secundário (Dissertação de Mestrado não publicada). Porto, Universidade Fernando Pessoa, Portugal.

FRA (2014). EU LGBT Survey European Union lesbian, gay, bisexual and transgender survey: Main results. Austria: FRA.

FRA (2016). Professionally speaking: challenges to achieving equality for LGBT people. Austria: FRA.

Friedman, M. S., Marshal, M. P., Guadamuz, T. E., Wei, C., Wong, C. F., Saewic, E. M., et al. (2011). A metanalysis of disparities in childhood sexual abuse, parental physical abuse, and peer victimization among sexual minority and sexual nonminority individuals. American Journal of Public Health, 101, 1481-1494. doi: 10.2105/AJPH.2009.190009

Gabriel, U., \& Banse, R. (2006). Helping behavior as a subtle measure of discrimination against lesbians and gay men: German data and a comparison across countries. Journal of Applied Social Psychology, 36(3), 690-707. doi:10.1111/j.0021-9029.2006.00025.x

Hawkins, L., Pepler, D., \& Craig, W. (2001). Naturalistic Observations of Peer Interventions in Bullying. Social Development, 10(4), 512-527. doi:10.1111/1467-9507.00178 
Herek, G. M. (2007). The psychology of sexual prejudice. Current Directions in Psychological Science, 9, 1922. doi: $10.1111 / 1467-8721.00051$

Holt, M. K., \& Espelage, D. L. (2007). Perceived social support among bullies, victims, and bully-victims. Journal of Youth and Adolescence, 36(8), 984-994. doi: 10.1007/s10964-006-9153-3

Hong, J., \& Espelage, D. (2012). A review of research on bullying and peer victimization in school: An ecological system analysis. Aggression and Violent Behavior, 17, 311-322. doi: 10.1016/j.avb.2012.03.003

Hong, J. S., \& Garbarino, J. (2012). Risk and Protective Factors for Homophobic Bullying in Schools: An Application of the Social-Ecological Framework. Educational Psychological Review, 24, 271-285.

ILGA (2016). A discriminação homofóbica e transfóbica em Portugal - 2016. Lisboa: ILGA.

ILGA (2018). Estudo Nacional sobre o Ambiente Escolar - Jovens LGBTI + - 2016/2017. Lisboa: ILGA.

Meyer, E. J. (2008). Gendered harassment in secondary schools: Understanding teachers' (non) interventions. Gender and Education, 20, 555-570. doi: 10.1080/ 09540250802213115

Misawa, M. (2009). Racist and homophobic bullying in adulthood: Narratives from gay men of color in higher education. New Horizons in Adult Education and Human Resource Development, 24(1), 7-23. Retrieved from http://education.fiu.edu/newhorizons

Moleiro, C., Pinto, N., Oliveira, J., \& Santos, H. (2016). Violência Doméstica: Boas práticas $\quad$ no apoio a vítimas LGBT. Lisboa: Comissão para a Cidadania e Igualdade de Género.

Monk, D. (2011) Challenging homophobic bullying in schools: the politics of progress. International Journal of Law in Context, 7(2), 181-207. doi:10.1017/S1744552311000061

Nogueira, C. (2001). Um novo olhar sobre as relações sociais de género. Feminismo e perspectivas críticas na Psicologia Social. Lisboa: Gulbenkian.

O'Higgins-Norman, J. (2008). Equality in the provision of social, personal and health education in the Republic of Ireland: the case of homophobic bullying? Pastoral Care in Education, 26, 2, 69-81. doi:10.1080/02643940802062568

Otero, L., \& Martínez, L. (2016). Sexismo y actitudes hacia la homosexualidad, la bisexualidad y transexualidad en estudiantes de Trabajo Social mexicano. Trabajo Social Global. Revista de Investigaciones en Intervención Social, 6(11), 3-30. Disponível em http://digibug.ugr.es/handle/10481/44260

Paulos, R. (2014). Observatório de Educação - Relatório de 2014. Lisboa: rede ex aequo.

Pimenta, N. S. (2013). Bullying em jovens LGBT (Dissertação de Mestrado não publicada). Viseu, Escola Superior de Educação de Viseu, Portugal.

Plummer, D. (2016). One of the Boys: Masculinity, Homophobia, and Modern Manhood. New York: Routledge.

Poteat, V., \& Espelage, D. (2005). Exploring the relation between bullying and homophobic verbal content: The Homophobic Content Agent Target (HCAT) Scale. Violence and Victims, 20, 513-528.

Poteat, V., \& Vecho, O. (2016). Who intervenes against homophobic behavior? Attributes that distinguish active bystanders. Journal of School Psychology, 54, 17-28. doi: 10.1016/j.jsp.2015.10.002

Poteat, V., \& DiGiovanni, C. D. (2010). When biased language use is associated with bullying and dominance behavior: The moderating effect of prejudice. Journal of Youth and Adolescence, 39, 1123-1133.

Presidência do Conselho de Ministros (2018). Resolução do Conselho de Ministros n.o ${ }^{\circ}$ 61/2018. Diário da República, 1.․ㅡ série - N. 97 - 21 de maio de 2018.

Rigby, K. (2005). Why do some children bully at school? School Psychology International, 26, 147-161. doi:10.1177\%2F0143034305052910

Robertson, L., \& Monsen, J. (2001). Issues in the Development of a Gay or Lesbian Identity: Practice Implications for Educational Psychologists. Educational and Child Psychology, 18(1), 13-31.

Rodrigues, L., Grave, R., Oliveira, J. M., \& Nogueira, C. (2016). Study on homophobic bullying in Portugal using Multiple Correspondence Analysis (MCA). Revista Latinoamericana de Psicologia, 48, 191200. doi:10.1016/j.rlp.2016.04.001

Rosa, F. A., Magalhães, M. J., Rodríguez-Castro, Y. and Lopez, R. (2018). Prevention of gender violence and working against LGBT prejudices: The intersection between collective action and institutional dynamics. International Journal of Iberian Studies, 31(1), 45-61. doi: 10.1386/ijis.31.1.45_1

Ryan, C., Huebner, D., Diaz, R., \& Sanchez, J. (2009). Family rejection as a predictor of negative health outcomes in white and Latino lesbian, gay, and bisexual young adults. Pediatrics, 123(1), 346-52. doi: $10.1542 /$ peds.2007-3524

Santos, H., Silva, S. M., \& Menezes, I. (2017). Para uma visão complexa do bullying homofóbico: desocultando o quotidiano da homofobia nas escolas. ex æquo, 36, 117-132. doi: 10.22355/exaequo.2017.36.07 
Scott, J. (1988). Gender and the politics of history. New York: Columbia University Press.

Smith, J., Twemlow, S. W., \& Hoover, D. H. (1999). Bullies, victims and bystanders: A method of in-school intervention and possible parental contributions. Child Psychiatry and Human Development, 30, 2937.

Torres, A. et al. (2018). Género na infância e juventude: Educação, trabalho, família e condições de vida em Portugal e na Europa. Lisboa: CIEG/ISCSP-ULisboa.

United Nations Educational, Scientific and Cultural Organization - UNESCO (2012). Review of Homophobic Bullying in Educational Institutions. Prepared for the International Consultation on Homophobic Bullying in Educational Institutions Rio de Janeiro, Brazil, 6-9 December 2011. Paris: UNESCO.

Utrilla, A. G. R., García, A. A. E., \& Yáñez, A. X. (2018). How to call what has many names? Bullying, gender violence, homophobia or discrimination against LGBTI people?. Revista interdisciplinaria de estudios de género de El Colegio de México, 4(e210). doi: 10.24201/eg.v4i0.210

Walton, G. (2005). "Bullying widespread": A critical analysis of research and public dis- course on bullying. Journal of School Violence, 4, 91-118. doi:10.1300/J202v04n01_06

$\begin{array}{lr}\text { Historial do } & \text { artigo } \\ \text { Recebido } & 03 / 2019 \\ \text { Aceite } & 12 / 2019 \\ \text { Publicado } & 12 / 2019\end{array}$

